UNIVERSIDADE ESTADUAL DE FEIRA DE SANTANA

Autorizada pelo Decreto Federal no 77.496 de 27/04/76

Recredenciamento pelo Decreto $\mathrm{n}^{\circ} 17.228$ de 25/11/2016

PRÓ-REITORIA DE PESQUISA E PÓS-GRADUAÇÃO

PPPG COORDENAÇÃO DE INICIAÇÃO CIENTÍFICA

XXIII SEMINÁRIO DE INICIAÇÃO CIENTÍFICA DA UEFS

SEMANA NACIONAL DE CIENTIÍFICA E TECNOLÓGICA - 2019

\title{
ANÁLISE TEMPORAL DA PERCEPÇÃO DE RISCOS EM COMUNIDADES TRADICIONAIS DE MADRE DE DEUS - BAHIA.
}

\author{
Brenda Elaine Silva de Jesus ${ }^{1}$; Fábio Pedro Souza de Ferreira Bandeira ${ }^{2}$ \\ 1. Bolsista PROBIC/UEFS, Graduanda em Ciências Biológicas, Universidade Estadual de Feira de Santana, \\ email: brenda._e@hotmail.com \\ 2. Orientador, Departamento de Ciências Biológicas, Universidade Estadual de Feira de Santana, email: \\ fpbandeira@gamail.com
}

PALAVRAS-CHAVE: Território, populações tradicionais e recursos pesqueiros.

\section{INTRODUÇÃO}

A Bahia possui o maior litoral da costa brasileira, dentro desse território está localizada a Baía de Todos os Santos (BTS), que é a segunda maior baía do país, apresentando uma área de $1.233 \mathrm{~km}$. A BTS detém de vasta riqueza ambiental composta de praias, penínsulas, enseadas e cabos distribuídos entre 13 municípios, alguns fundados no início da colonização do Brasil, em consequência as comunidades se assemelham por características culturais ou por meio do sistema hídrico e de navegação (CAROSO, et al 2011).

Por possuir paisagem natural e território de ocupação indígena a BTS é o portal de entrada que abrigou posteriormente populações, vilas e cidades (CRA, 2001 ). Nesse contexto são inseridas as comunidades tradicionais, Segundo a Constituição Federal (BRASIL, 2007) os povos tradicionais são grupos culturalmente diferenciados e que se reconhecem como tais, que possuem formas próprias de organização social, que ocupam e usam territórios e recursos naturais como condição para sua reprodução cultural, social, religiosa, ancestral e econômica, utilizando conhecimentos, inovações e práticas geradas e transmitidas pela tradição.

No passado o território da BTS passou por diversas modificações, suas áreas eram compostas de densas florestas e bosques de manguezais que foram destruídos com a instalação dos engenhos e do cultivo da primeira monocultura de exportação do país. Nesse cenário o ambiente natural foi devastado e a vegetação foi empregada na construção de embarcações e como combustível (HATJE, et al 2011) .

No que diz respeito à percepção, o risco é considerado a avaliação das pessoas acerca de algum assunto que envolve situações de perigo, unindo fatores pessoais e sociais, 
que entre outros, propõe a multidimensionalidade da percepção dele (MARANDOLA Jr; HOGAN, 2004).

Devido a grande pressão de ocupação na sua zona costeira e pelos diversos usos de sua riqueza natural, a BTS e suas comunidades tradicionais possuem uma grande vulnerabilidade, resultante dos diversos impactos gerados na região. Sendo assim é necessário um levantamento detalhado ao longo dos anos, no ambiente em que as populações tradicionais da BTS estão relacionadas para dispor da percepção risco.

\section{MATERIAL E MÉTODOS OU METODOLOGIA}

Segundo o IBGE (2018) Madre de Deus é uma ilha com área territorial de $32.201 \mathrm{~km}^{2} \mathrm{e}$ população estimada no último censo de 17.376 pessoas. Devido a beleza natural de suas praias a cidade passou a ser ponto turístico, antes disso na década 1950, deu-se início nas atividades petrolíferas sem que houvesse contingenciamento do governo ou uma preocupação com a sociedade e com as consequências dos impactos ambientais decorrentes da produção (HATJE,2018).

Visando a coleta de dados, o estudo etnoecológico teve o enfoque em abordagens construídas através de um conjunto de observações da percepção de riscos da comunidade de Madre de Deus ao longo do tempo. Com o objetivo de identificar as questões territoriais e compreender os riscos e vulnerabilidades presentes na área de estudo foram realizadas viagens de campo entre os meses de janeiro a junho de 2019.

A abordagem quantitativa foi realizada através de entrevistas em profundidade, cenário em que o entrevistado é livre para expressar suas emoções, vivências e opiniões que constituem suas experiências de vida (MORÉ, 2015). As entrevistas foram semiestruturadas ou não estruturadas, realizadas com interlocutores chaves (pescadores e marisqueiras) residentes do município de Madre de Deus, utilizou-se o consentimento livre esclarecido.

Nessa pesquisa utilizaram-se dados secundários do estudo etnográfico que ocorreu entre os anos de 2012 - 2015 pelo projeto guarda chuva, sendo também baseado em entrevistas realizadas no ano de 2019 que foram utilizadas para a análise temporal. Após a análise de conteúdo, os dados coletados foram interpretados e sistematizados definindo categorias específicas da percepção de riscos da comunidade. Os dados das entrevistas foram graficados com o uso do programa Excel.

\section{RESULTADOS E/OU DISCUSSÃO}

Nos dados obtidos pela base de informações do Projeto guarda-chuva foram observados 23 fatores percebidos como risco por pescadores e marisqueiras (além da população não envolvida com a pesca). São eles em ordem decrescente de citação: Poluição da água (PolAg), Violência associada ao tráfico de drogas (ViTr), Poluição do ar (PolAr), Ausência de saneamento Básico (FaSb), Sistema de saúde deficitário (SiSad), Poluição Sonora urbana (PolSo), Restrição das áreas pesqueiras pelas atividades industriais (ResAp), Pesca Predatória com bomba (PPrB), Maré vermelha (MaVe), Desmatamento (Desm), Mudança cultural na pesca (MdCuP), Inundações em períodos chuvosos ( Inud ), Expansão urbana em áreas de manguezal (ExUb), Conflitos territoriais urbanos (Cfter), Falta de infraestrutura para comercialização do pescado (InfCom), Conflito por sobreposição de área de pesca (CfAP), Poluição industrial petroquímica do solo 
(PolSol), Assoreamento (Ass), Exploração sexual infantil e juvenil (ExpSex), Danos aos petrechos de pesca por instalações industriais no mar (DanPet), Poluição por resíduos sólidos associada ao turismo (PolRS), Segurança pública insuficiente (SegPul), Risco de explosão de instalações industriais (tubulações) (TubExp).

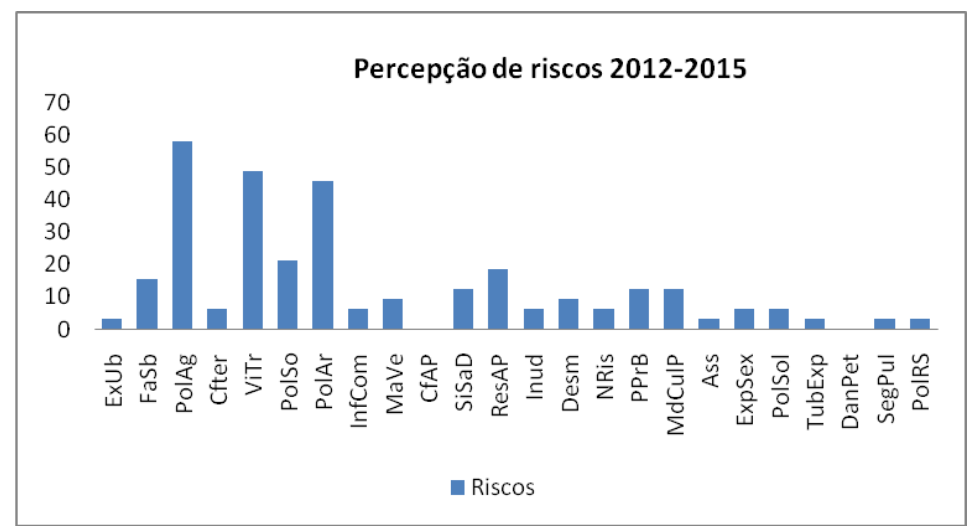

Figura 1 - Frequência de citação dos riscos percebidos pela comunidade nos anos entre 2012 a 2015

Os fatores de riscos mais citados da base de dados foram: A poluição da água (PolAg), Violência associada ao tráfico de drogas (ViTr), Poluição do ar (PolAr), Ausência de saneamento Básico ( $\mathrm{FaSb}$ ), Sistema de saúde deficitário ( $\mathrm{SiSad}$ ), Poluição Sonora urbana (PolSo) foram os fatores de riscos mais citados e estão relacionados à atividade industrial e petroquímica, como também está associado com o fato de Madre de Deus e Candeias fazerem parte da região metropolitana de Salvador, aumentando o índice populacional nesses municípios. Os mesmos fatores de riscos foram analisados na coleta de dados realizada no ano de 2019. Os riscos mais citados foram PolAr, PolAg, ResAP, TubExp, DanPet e MdCulP.

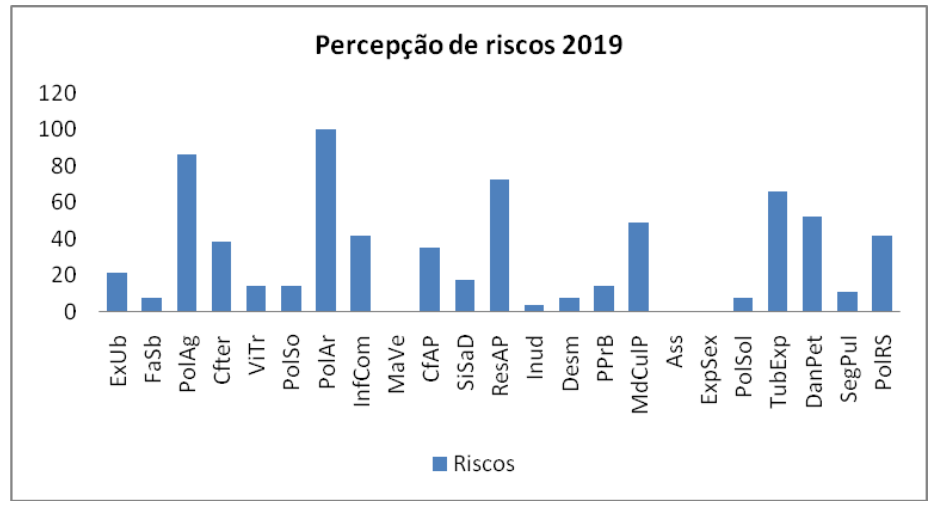

Figura 2 - Frequência de citação de riscos percebidos no ano de 2019.

\section{ANÁLISE DA FREQUÊNCIA DE CITAÇÃO GERAL}

Os riscos foram citados por quase todos os entrevistados, ocorrendo diferenças na magnitude da variação de alguns deles como Poluição do ar (PolAr), poluição da água (PolAg), Restrição a áreas pesqueiras (ResAP), Tubulações expostas (TubExp), Danos nos petrechos pesqueiros (DanPet) e Mudança na cultura da pesca (MdCulP) com maior frequência de citação, devido a ocupação de parte do território de Madre de Deus por 
indústrias petroquímicas o que restringe as áreas pesqueiras, além de poluir o ar através da eliminação de resíduos na atmosfera.

Nos dados secundários (2012-2015) os riscos de Danos nos petrechos pesqueiros (DanPet), e Conflitos em áreas pesqueiras (CfAP) não foram citados, porém esses riscos foram percebidos pelos entrevistados em 2019. O risco de Maré vermelha (MaVe), Assoreamento (Ass) e Exploração sexual infantil (ExpSex) foi citado em 2012-2015 e não foi observado nos dados de 2019. O risco de MaVe está relacionado a um episódio que ocorreu no ano de 2007 na BTS (Figura 1 e 2).

Levando em consideração a análise de riscos de citação por gênero, não houve diferenças significativas nos dois estudos (2012-2015 e 2019), sendo percebidos de maneira similar por homens e mulheres.

\section{CONCLUSÃo}

A partir dos resultados obtidos nessa pesquisa e na base de dados, conclui-se que a PolAg, Polar são os riscos mais percebidos pelos entrevistados em Madre de Deus. Esses riscos estão associados a presença de empreendimentos industriais na cidade, resultando em maior vulnerabilidade da comunidade tradicional de pescadores.

As alterações ambientais causadas pelos impactos gerados pela presença dos empreendimentos industriais, trazem uma série de vulnerabilidades que afetam diretamente a vida de pescadores e marisqueiras. Sendo assim, as informações obtidas nesse estudo são de extrema importância para implantação de monitoramento ambiental participativo nas comunidades, e uma maior atuação junto ao poder público para controlar os impactos ambientais que mais afligem as comunidades tradicionais da BTS.

\section{REFERÊNCIAS}

BRASIL(a). Decreto s/n de 27 de dezembro de 2004. Presidência da República. Casa Civil. Subchefia de Assuntos Jurídicos. Acesso: http://www.planalto.gov.br/ccivil_03/_Ato2004-2006/2004/Dnn/Dnn10408.htm, em 10.jun2010.

CRA. Avaliação das áreas costeiras superficiais, BTS Praias de Salvador. Salvador/BA, março/ 2001.

CAROSO, Carlos; TAVARES, Fátima; PEREIRA, Cláudio Luiz. Baía de Todos os Santos: aspectos humanos. EDUFBA, 2011.

HATJE et al. Baía de Todos os Santos - Avanços nos estudos de longo prazo. Disponível em:< http://www.institutokirimure.pro.br/wp-content/uploads/2018/09/BTS3_digital.pdf $>$. Acesso em: 01, Agt de 2019.

IBGE, 2018. Disponível em:< https://cidades.ibge.gov.br/brasil/ba/madre-de-deus/panorama $>$. Acesso em: 01, Agt de 2019.

MORÉ, Carmen. A “entrevista em profundidade" ou "semiestruturada", no contexto da saúde Dilemas epistemológicos e desafios de sua construção e aplicação. CIAIQ2015, v. 3, 2015.

MARANDOLA JR., Eduardo; HOGAN, Daniel J. O risco em perspectiva: tendências e abordagens. Geosul, Florianópolis, n. 38, p. 23-58, 2004. 